\title{
IDENTIFIKASI SEBARAN DAN TINGKAT KESUBURAN MANGROVE MELALUI PEMANTAUAN INDEKS VEGETASI DARI SATELIT LANDSAT 7.0 ETM+ MENGGUNAKAN FUZZY LOGIC (Studi Kasus Pantai Pesisir Timur Surabaya / Pamurbaya)
}

\author{
Oleh: \\ Dhyah Wulandari ${ }^{1}$, Farid Samsu $\mathrm{H}^{2}$.
}

\begin{abstract}
ABSTRAK: Mangrove adalah tanaman pepohonan hidup diantara laut dan daratan, yang pertumbuhannya dipengaruhi oleh pasang-surut. Mangrove dapat dimanfaatkan sebagai biomassa dan juga memiliki aspek-aspek ekologis. Berkaitan dengan perkembangan teknologi yang semakin pesat, membuat manusia melakukan model pendekatan untuk melakukan komputasi dengan meniru akal manusia yang salah satunya yaitu sistem Fuzzy Logic. Fuzzy Logic merupakan pengambilan keputusan yang sesuai untuk konsep tidak pasti.Dengan memanfaatkan Citra Landsat 7.0 ETM+ dapat mempermudah mendapatkan informasi tanpa menyentuh objek penelitian. Penelitian ini bertujuan untuk mengetahui luas dan sebaran serta tingkat kesuburan mangrove di wilayah Pamurbaya pada tahun 2002 bulan September.

Tahapan penelitian terdapat 3 bagian, yaitu: pengolahan citra Landsat, pengambilan data, dan pengolahan data. Pengolahan citra Landsat bertujuan mengkombinasi saluran yang dibutuhkan untuk analisis citra. Pengambilan data meliputi NDVI, LAI, Kerapatan dan Suhu permukaan. Pengolahan data bertujuan untuk menghitung luas, mengamati sebaran mangrove, dan mengetahui tingkat kesuburannya menggunakan Logika Fuzzy. Digunakan 3 variabel inputan sebagai karakteristik kesuburan mangrove yaitu NDVI, Kerapatan dan Suhu pemukaan.

Dari proses tersebut, diperoleh hasil penelitian, bahwa luas mangrove wilayah Pamurbaya pada tahun 2002 mencapai 4.838 Ha sedangkan sebarannya meliputi Kecamatan Sukolilo, Rungkut dan Gunung Anyar. Enam titik di Kecamatan Sukolilo memiliki status tingkat kesuburan subur tingkat rendah dengan nilai kesuburan 50 dan satu titik memiliki status tingkat kesuburan sedang tingkat rendah dengan nilai kesuburan 21,94. Tiga titik di Kecamatan Rungkut mengalami status tingkat kesuburan tingkat rendah dan satu titik memiliki status tidak subur dengan nilai kesuburan 14,13. Satu titik di Kecamatan Gunung Anyar dengan status tingkat kesuburan subur tingkat rendah dengan nilai kesuburan 50. Hasil ini ditampilkan pada GUI Matlab untuk mempermudah dalam mengetahui sebaran mangrove dan titik-titik pengambilan data.
\end{abstract}

Kata Kunci : Citra Landsat 7.0 ETM+, NDVI, LAI, kerapatan, suhu permukaan, fuzzy logic, GUI Matlab.

\begin{abstract}
ABSTRACK: Mangrove plants, are trees living among marine and landlocked affected by tidal. Mangrove can be utilized as ecological and biomass which that growth also has aspects. As the development of information technology is utilized a model approach for computing the fuzzy systems. Fuzzy systems is decision making according to the concept.By utilizing Landsat ETM+ Imagery 7.0 can make getting information without touching the object of research. This research aims to know the wide spread and level/quality of fertility in the region of mangrove Pamurbaya in September, in 2002. This research, there are 3 stages, namely: processing image landsat, retrieval data, and data processing. Processing image landsat aims to combine channel required for analysis image analysis. Adoption of data on image composite covering NDVI, LAI, Density and temperature surface. Data processing aims counting mangrove broad, observing mangrove scatter, and knowing the fertility level that uses making Fuzzy Logic.Used 3 input variables as mangrove fertility characteristics, namely NDVI, Density and Temperature Surface.

Of more or less in accordance, the result of this research,that mangrove broad in region Pamurbaya in 2002 reached 4.838 ha while that scatter include Sukolilo Subdistrict, Rungkut and Gunung Anyar. Six points in the Sukolilo subdistrict has level statue of that fertility on the statue of fertile is a low
\end{abstract}

1,2 Jurusan Fisika, FakultasSains dan Teknologi, UIN Maliki Malang 
level with fertility value 50 and one point has level statue of that fertility on the statue of moderate fertile is a low level with fertility 21,94 . Three points in the Rungkut subdistrict has level statue of that fertility on the statue of fertile is a low level and one point has infertile statue with fertility value 14,13. One point in the Gunung Anyar subdistrict has level statue of that fertility on the statue of fertile is a low level with fertility value 50. The result was displayed in GUI matlab to ease in knowing pinpricks of the collecting.

Keywords: Image of Landsat 7.0 ETM+, NDVI, LAI, Density, Surface Temperatures, Fuzzy Logic, GUI Matlab.

\section{PENDAHULUAN}

Indonesia merupakan negara kepulauan (archipelago country) dengan wilayah mangrove terluas di dunia. Potensi ini didukung oleh panjang garis pantainya yang mencapai $+81.000 \mathrm{~km}$ dan menjadikan Indonesia sebagai negara dengan garis pantai terpanjang kedua di dunia setelah Kanada. Mangrove adalah tanaman pepohonan atau komunitas tanaman yang hidup diantara laut dan daratan yang dipengaruhi oleh pasangsurut [1].

Indeks vegetasi adalah besaran nilai kehijauan vegetasi yang diperoleh dari pengolahan sinyal dijitaldata nilai kecerahan (brightness) beberapa kanal datasensor satelit. Untuk pemantauan vegetasi, dilakukanproses pembandingan antara tingkat kecerahan kanalcahaya merah (red) dan kanal cahaya inframerah dekat(near infrared). Fenomena penyerapan cahaya meraholeh klorofil dan pemantulan cahaya inframerah dekatoleh jaringan mesofil yang terdapat pada daun akanmembuat nilai kecerahan yang diterima sensor satelitpada kanal-kanal tersebut akan jauh berbeda. Padadaratan non-vegetasi, termasuk diantaranya wilayahperairan, pemukiman penduduk, tanah kosongterbuka, dan wilayah dengan kondisi vegetasi yangrusak, tidak akan menunjukkan nilai rasio yang tinggi (minimum) [7].

Nilai perbandingan kecerahan kanal cahaya merahdengan cahaya inframerah dekat atau NIR/RED, adalah nilai suatu indeks vegetasi (yang sering disebut"simple ratio") yang sudah tidak dipakai lagi. Hal inidisebabkan karena nilai dari rasio NIR/RED akanmemberikan nilai yang sangat besar untuk tumbuhanyang sehat. Oleh karena itu, dikembangkanlah suatualgoritma indeks vegetasi yang baru dengannormalisasi, yaitu NDVI (Normalized DifferenceVegetation Index) seperti berikut ini [7]:

$$
N D V I=\frac{\left[\left(\frac{N I R}{R E D}\right)-1\right]}{\left[\left(\frac{N I R}{R E D}\right)+1\right]}
$$

yang ekuivalen dengan:

$$
N D V I=\frac{N I R-R E D}{N I R+R E D}
$$

Indeks vegetasi berbasis NDVI yang ditunjukkan pada persamaan (2), mempunyai nilai yang hanya berkisarantara -1 (non-vegetasi) hingga 1 (vegetasi).

Gambar 1 menunjukkan bahwa untuk wilayah yangmempunyai nilai tingkat kehijauan vegetasi NDVI dibawah 0.2, maka wilayah tersebut sudah keluar dari kelompok vegetasi (karena bisa berupa wilayahperairan atau tanah bebatuan). Untuk wilayah yangmempunyai NDVI bernilai di atas 0.4 , dapatdisimpulkan wilayah tersebut merupakan kawasanyang ditutupi hutan yang lebat dan subur [7]: 


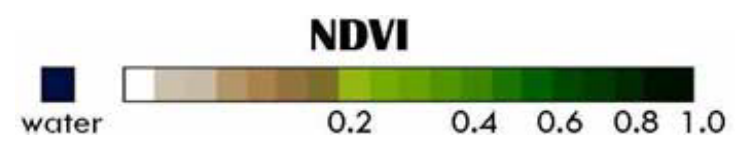

Gambar 1. Rentang data NDVI oleh NASA

Untuk menganalisis kualitas mangrove melalui data penginderaan jauh dapat digunakan metode indeks vegetasi ternormalisasi NDVI (Normalized Difference Vegetation Index). Metode perhitungan ini akan membagi tingkat kesehatan mangrove berdasarkan nilai kerapatan kanopi, diantaranya [2].

1. $<=20 \%$ (Sangat Jarang), kisaran nilai NDVI $>0,01$ sampai 0,18

2. $21,40 \%$ (Jarang), kisaran nilai NDVI 0,18 sampai 0,32

3. $\quad 41,60 \%$ (Sedang), kisaran nilai NDVI 0,32 sampai 0,42

4. $\quad 61,80 \%$ (Lebat), kisaran nilaii NDVI 0,42 sampai 0,47

5. $>=80 \%$ (Sangat Lebat), kisaran nilai $>=0,47$.

LAI (Leaf Area Index) didefinisikan sebagai luas daun (yang diproyeksikan pada bidang datar) setiap unit luas permukaan tanah yang tertutupi kanopi pohon. LAI dapat diestimasi denganmenggunakan parameter NDVI dengan terlebih dahulu mengetahui jenis tutupan vegetasi yang ada [3].

Suhu permukaan merupakan suatu parameter yang sensitif terhadap keberadaan dan jenis vegetasi yang menutupi objek kajian, dan juga kelembaban udara maupun kelengasan permukaan. Parameter-parameter diatas akan mempengaruhi variasi suhu baik yang bersifat temporal maupun spasial suatu permukaan. Pada dasarnya estimasi suhu permukaan dengan menggunakan citra satelit memanfaatkan konsep emisi gelombang elektro magnetik benda yang memiliki keunikan berdasarkan suhu permukaan. Benda dengan suhu berbeda akan mengemisikan gelombang elektromagnetik maksimum pada kisaran panjang gelombang yang berbeda-beda [4].

Pada citra satelit terdapat beberapa saluran (channel) untuk mengumpulkan dan menyimpan informasi pada tiap panjang gelombang yang berdekatan yang dinamakan layer (band). Kumpulan dari beberapa layer spektral pada daerah dan waktu yang sama dinamakan citra multispektral. Terdapat banyak aplikasi dari data Landsat TM: pemetaan penutupanlahan, pemetaan penggunaan lahan, pemetaan tanah, pemetaan geologi,pemetaan suhu permukaan laut dan lain-lain [5].

Fuzzy logicmerupakan teknik untuk mengolah istilah linguistik. Pendekatan Fuzzy logicberhubungan dengan jenis ketidakpastian atau ketidakjelasan yang telah menjadi sifat alamiah manusia. Pengetahuan yang tidak pasti dan pertimbangan yang tidak presisi adalah asek penting keahlian dalam menerapkan akal sehat dalam situasi pengambilan keputusan. Dalam fuzzy logic, nilai benar atau salah digantikan dengan derajat pada himpunan keanggotaan. Misalnya, dalam logika boolean tradisional, catatan kredit seseorang adalah baik atau buruk. Dalam fuzzy logic, catatan kredit tersebut dapat disebut baik atau buruk, tetapi masing-masing memiliki derajat yang berbeda [6].

Penelitian ini bertujuan untuk mengetahui luas dan sebaran mangrove, serta untuk mendapatkan informasi tentang tingkat kesuburan mangrove. Data yang digunakan dalam penelitian ini adalah citra Landsat ETM+ tahun 2002 path/row 118/65 tahun 2002 bulan September. 
Metode penelitian ini terdiri dari 3 tahapan, yaitu pengolahan citra landsat, pengambilan data dan pengolahan data. Pengolahan data bertujuan mengkombinasi citra komposit, pengambilan data terdiri dari data NDVI, LAI, Kerapatan dan Suhu permukaan. Pengolahan data menggunakan pengambilan keputusan Fuzzy Logic untuk menentukan nilai dan status tingkat kesuburan mangrove.

\section{HASIL DAN PEMBAHASAN}

1. Hasil pengolahan Citra Landsat 7.0 ETM+

Hasil dari mengkombinasikan saluran-saluran TM pada citra untuk mengamati objek NDVI dan Suhu permukaan wilayah Pamurbaya tahun 2002 diperoleh kenampakan citra seperti pada gambar dibawah ini. Saluran TM 3, 2, 1 untuk menampilkan keadaan awal (asli) sesuai lapangan. Saluran TM 4, 5, 3 untuk menampilkan keberadaan mangrove. Saluran TM 6 untuk menampilkan suhu permukaan.
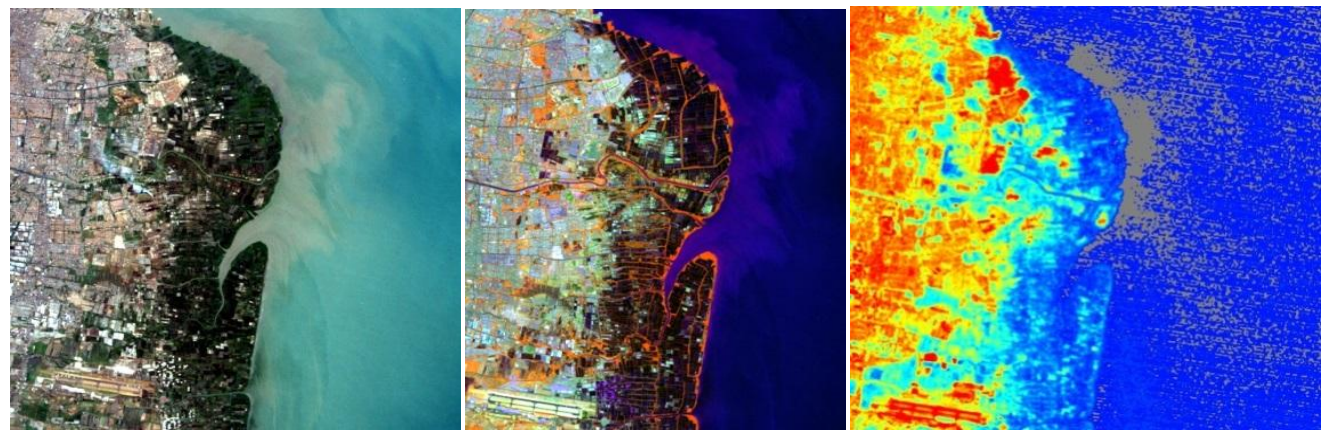

Gambar 2. Saluran TM 3, 2, 1 Gambar 3. Saluran TM 4, 5, 3 Gambar 4. Saluran TM 6

Untuk mengamati suhu permukaan digunakan gelombang infra merah thermal karena sesuai berdasarkan karakterisitiknya untuk mengamati suhu permukaan dan kelembaban tanah. Hasil kenampakan citra dengan menggunakan saluran TM 6 adalah suhu yang dingin ditampakkan dengan warna biru, ini didominasi oleh vegetasi.Sedangkan suhu yang sedang hingga panas ditampakkan dengan warna kuning-kemerahan, ini didominasi pemukiman, pabrik dll.

\section{Hasil Pengambilan Data}

Berikut adalah data hasil wilayah Pamurbaya tahun 2002 seperti pada Tabel 1.

Tabel 1. Data hasil wilayah Pamurbaya tahun 2002

\begin{tabular}{|ccccccc|}
\hline No & $\begin{array}{c}\text { Easting } \\
(\mathrm{E})\end{array}$ & Norting(N) & $\begin{array}{c}\text { Nilai DN } \\
\text { NDVI }\end{array}$ & LAI & $\begin{array}{c}\text { Kerapatan } \\
(\%)\end{array}$ & $\begin{array}{c}\text { DN suhu } \\
(0 \mathrm{C})\end{array}$ \\
\hline 1. & 699703,01 & $-80241,50$ & 0,256 & 0,3206 & 26,0818 & 21,7372 \\
\hline 2. & 699371,48 & $-802355,04$ & 0,430 & 0,7314 & 66,3110 & 21,8944 \\
\hline 3. & 700142,03 & $-802873,95$ & 0,874 & 5,9983 & 68,0142 & 22,3661 \\
\hline 4. & 701898,75 & $-803556,21$ & 0,345 & 0,4889 & 48,4718 & 21,7372 \\
\hline 5. & 703590,00 & $-805276,29$ & 0,808 & 4,3871 & 80,2783 & 21,7372 \\
\hline 6. & 703705,31 & $-806563,95$ & 0,202 & 0,2882 & 11,0731 & 21,5800 \\
\hline
\end{tabular}




\begin{tabular}{|rrrrrrr|}
\hline 7. & 703023,05 & $-813280,90$ & 0,519 & 1,1152 & 80,2910 & 21,8944 \\
\hline 8. & 703541,95 & $-808639,57$ & 0,510 & 1,0686 & 79,1245 & 21,7372 \\
\hline 9. & 701485,55 & $-805362,77$ & 0,824 & 4,7327 & 77,7830 & 22,3661 \\
\hline 10. & 703263,28 & $-806727,30$ & 0,414 & 0,6780 & 63,2599 & 21,7372 \\
\hline
\end{tabular}

3. Pengolahan Data

3.1 Hasil pengolahan data luas mangrove

Luas mangrove diperoleh dari data citra RGB dirubah ke grayscale dengan menggunakan algoritma baca nilai piksel citra. Dari algoritma tersebut diperoleh hasil luas mangrove wilayah Pamurbaya tahun 2002 adalah $48383100 \mathrm{~m}^{2}$ atau 4.838 Ha. Hasil ini mendekati dengan hasil pengukuran lapangan. Penetuan batas wilayah mangrove pada citra yang menjadikan perbedaan nilai luas mangrove dengan kondisi di lapangan.

3.2 Hasil pengolahan data tingkat kesuburan mangrove

Penentuan nilai dan status kesuburan mangrove digunakan metode Fuzyy Logic metode Mamdani. Terdapat 4 tahapan untuk mendapatkan output, yaitu:

1. Pembentukan himpunan Fuzzy

Variabel input dan output dibagi menjadi satu atau lebih himpunan fuzzy. Pada penelitian ini menggunakan 3 variabel. Seperti pada Tabel 2. Dari variabel tersebut kemudian disusun domain himpunan fuzzy.

Tabel 2. Semesta pembicara untuk tiap variabel

\begin{tabular}{|lcc|}
\hline Fungsi & Nama Variabel & Semesta Pembicara \\
\hline Masukan & NDVI & {$[0,1]$} \\
\hline & Kerapatan & {$[0 \%, 100 \%]$} \\
\hline & Suhu Permukaan & {$[00 \mathrm{C}, 400 \mathrm{C}]$} \\
\hline Keluaran & Status Kesuburan & {$[0,90]$} \\
\hline
\end{tabular}

2. Aplikasi Fungsi Implikasi

Aplikasi fungsi implikasi bertujuan untuk pembentukan aturanaturan yang menyataan relasi dan hubungan antara variabel input dan variabel output. Dalam metode Mamdani digunakan fungsi impliksi Min.Aturan-aturan yang dibuat sebagai berikut:

$$
\text { If.... and..... then.... }
$$

3. Komposisi Aturan

Dari hasi aplikasi fungsi implikasi dari tiap aturan, digunakan metode Max untuk melalkukan komposisi antar semua aturan. 
4. Penegasan (Defuzzyfikasi)

Defuzzyfikasi adalah hasil akhir. Setelah dilakukan tahapan-tahapan di atas untuk mendapatkan output, maka diperoleh hasil perhitungan untuk nilai dan status kesuburan seperti pada Tabel 3 berikut.

Tabel 3. Data hasil nilai dan status kesuburan mangrove Pamurbaya tahun 2002

\begin{tabular}{|c|c|c|c|c|c|}
\hline No & $\begin{array}{l}\text { Nilai } \\
\text { NDVI }\end{array}$ & $\begin{array}{l}\text { Kerapa- } \\
\tan (\%)\end{array}$ & $\begin{array}{l}\text { Suhu } \\
(0 \mathrm{C})\end{array}$ & $\begin{array}{c}\text { Nilai } \\
\text { Kesu-buran }\end{array}$ & $\begin{array}{c}\text { Status } \\
\text { kesuburan }\end{array}$ \\
\hline 1. & 0,256 & 26,08 & 21,74 & 21,94 & $\begin{array}{l}\text { Sedang tingkat } \\
\text { rendah }\end{array}$ \\
\hline 2. & 0,430 & 66,31 & 21,90 & 50 & $\begin{array}{l}\text { Subur tingkat } \\
\text { rendah }\end{array}$ \\
\hline 3. & 0,874 & 68,01 & 22,37 & 50 & $\begin{array}{c}\text { Subur tingkat } \\
\text { rendah }\end{array}$ \\
\hline 4. & 0,345 & 48,47 & 21,74 & 34,81 & Sedang \\
\hline 5. & 0,808 & 80,28 & 21,74 & 50 & $\begin{array}{l}\text { Subur tingkat } \\
\text { rendah }\end{array}$ \\
\hline 6. & 0,202 & 11,07 & 21,58 & 14,13 & Tidak subur \\
\hline 7. & 0,519 & 80,29 & 21,89 & 50 & $\begin{array}{l}\text { Subur tingkat } \\
\text { rendah }\end{array}$ \\
\hline 8. & 0,510 & 79,15 & 21,74 & 50 & $\begin{array}{l}\text { Subur tingkat } \\
\text { rendah }\end{array}$ \\
\hline 9. & 0,824 & 77,78 & 22,37 & 50 & $\begin{array}{l}\text { Subur tingkat } \\
\text { rendah }\end{array}$ \\
\hline 10. & 0,414 & 63,26 & 21,74 & 50 & $\begin{array}{l}\text { Subur tingkat } \\
\text { rendah }\end{array}$ \\
\hline
\end{tabular}

Dari hasil tersebut sesuai dengan hasil lapangan yang dibandingkan dengan informasi yang diperoleh dari artikel yang ditulis oleh Edy (2009) tentang ekosistem pesisir kota Surabaya tahun 2002 bahwa mangrove di wilayah Pamurabaya mengalami kerusakan berat sebagian.

Representasi GUI Matlab untuk mempermudah dalam menampilkan hasil penelitian seperti pada Gambar 5 dan 6 berikut ini: 


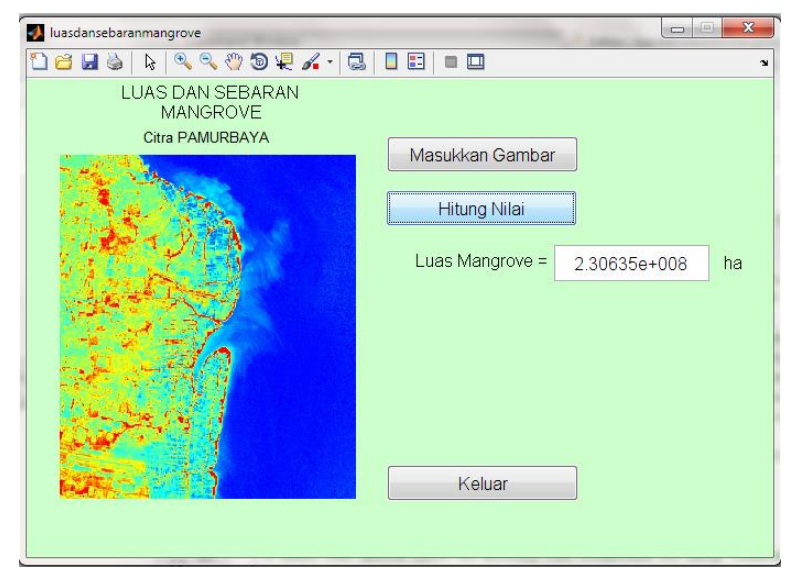

Gambar 5. GUI untuk luas sebaran mangrove

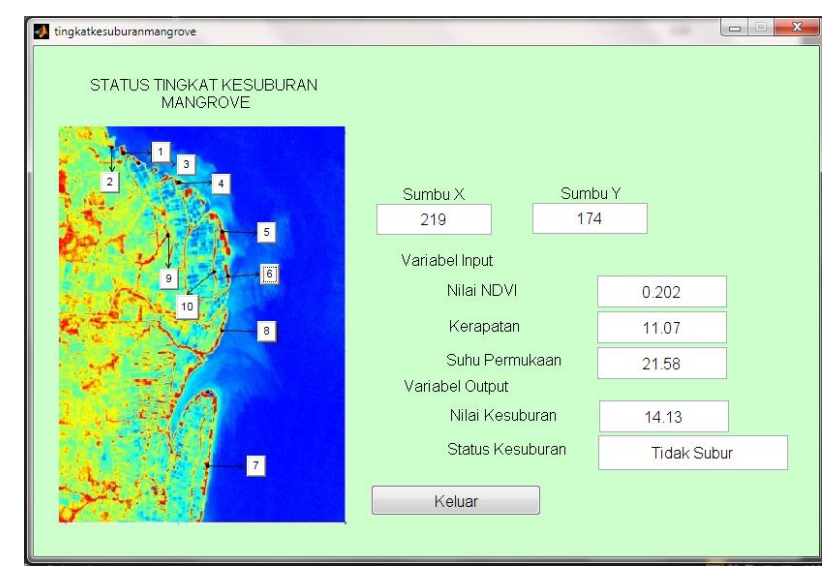

Gambar 6. GUI untuk tingkat kesuburan mangrove

\section{KESIMPULAN}

a. Hasil luas mangrove wilayah Pamurbaya tahun 2002 adalah 4.838,3 Ha dengan sebarannya meliputi Kecamatan Rungkut, Sukolilo dan Gunung Anyar.

b. Hasil tingkat kesuburan mangrove yang meliputi 10 titik di wilayah Pamurbaya adalah: Titik 1, 2, 3, 4, 5 dan 9 yang berada di Kecamatan Sukolilo memiliki status tingkat kesuburan subur tingkat rendah dengan nilai kesuburan 50 kecuali pada titik 1 memiliki status tingkat kesuburan sedang tingkat rendah dengan nilai kesuburan 21,94. Titik 6, 8 dan 10 berada di Kecamatan Rungkut mengalami status tingkat kesuburan tingkat rendah kecuali pada titik 6 memiliki status tidak subur dengan nilai kesuburan 14,13. Titik 7 berada di Kecamatan Gunung Anyar dengan status tingkat kesuburan subur tingkat rendah dengan nilai kesuburan 50. Dari hasil tersebut menyatakan bahwa persebaran mangrove di Pamurbaya tidak merata.

\section{DAFTAR PUSTAKA}

[1] Forestian, Oktama. 2011. Estimasi Biomassa dan Kerapatan Vegetasi Mangrove Menggunakan Data Landsat ETM+ (Studi di Hutan Lindung dan Hutan Produksi Tetap Muara Gembong, Kabupaten Bekasi, Propinsi Jawa Barat). IPB. Bogor. 
[2] Jhannerie dkk, 2006. Deteksi Perubahan Luasan Hutan Mangrove dengan Menggunakan Penginderaan Jauh dan Sistem Informsi Geografis di Kota Dumai Propinsi Riau. Pekanbaru: Universitas Riau.

[3] Suwarsono. 2010. Pengembangan Metode Penetuan Indeks Luas Daun dari Data Satelit Penginderaan Jauh. Jakarta: LAPAN.

[4] Ilham, Muhammad. 2012. Perbandingan Beberapa Aturan Fusi Citra Berbasis Wavelet Pada Citra Landsat Etm. Banda Aceh: Universitas Syiah Kuala.

[5] Javed, Mallick. dkk. 2008. Estimation of Land Surface Temperature Over Delhi using Landsat-7 ETM+. Jerman: Ind. Geopys.

[6] Kusumadewi, Sri. 2003. Artificial Intelligence (Teknik dan aplikasinya). Yogyakarta: Graha Ilmu.

[7] Sudiana, Dodi dan Diasmara, Elfa. 2008. Analisis Indeks Vegetasi menggunakan Data Satelit NOAA/AVHRR dan TERRA/AQUA-MODIS. Depok: Universitas Indonesia (UI). 